Quarterly Journal of the Geological Society

\title{
Description of the Mouth of a Hybodus found by Mr. Boscawen Ibbetson in the Isle of Wight
}

Philip Malpas de Grey Egerton

Quarterly Journal of the Geological Society 1845, v.1; p197-199.

doi: 10.1144/GSL.JGS.1845.001.01.51

\section{Email alerting service}

Permission request

Subscribe click here to receive free e-mail alerts when new articles cite this article

click here to seek permission to re-use all or part of this article

click here to subscribe to Quarterly Journal of the Geological Society or the Lyell Collection

Notes 


\section{Thickness and Description of Strata.}

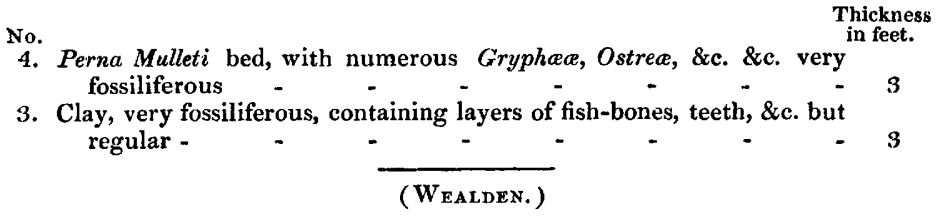

In the accompanying Table are given the ranges of such of the fossils of the above strata as were collected and noted by the authors on the spot.

5. Description of the Mouth of a HrBodus found by Mr. Boscawen Ibbetson in the Isle of Wight. By Sir Philip Malpas de Grey Egerton, Bart. M.P. F.R.S. F.G.S.

THE present memoir is the result of the examination of an Ichthyolite discovered by Mr. Boscawen Ibbetson in the Isle of Wight, near the junction of the Lower Green Sand with the Wealden, and sent to me in the hopes that it might tend to show to which of the two formations this bed should be assigned. The evidence it affords on this question is neither direct nor conclusive, inasmuch as it is an undescribed species, and consequently any deductions beyond those based upon general affinities would be unwarrantable. In another point of view, however, this specimen is of high scientific value, as it sets at rest the long-mooted questions of the relative characters of the upper and lower teeth, and their general contour in the individuals composing the genus $\mathbf{H y}$ bodus so extensively occurring in the secondary strata. Mr. Ibbetson has had the rare fortune to bring to light the entire mouth of a fish of this genus. The left side is slightly crushed, but the other retains its natural form, and the greater portion of the teeth in both the upper and the lower jaw. The former measures 10inches, and appears to have carried twenty-four teeth in the front series; the latter measures $7 \frac{1}{2}$ inches, and has nineteen teeth in series, one on the symphysis and nine on either side. Two rows of succession teeth are traceable behind the front series. The mouth is slightly open, and when seen in profile is more arcuate than in the recent sharks. The upper jaw has a broad notch for the reception of the thickened symphysis of the lower mandible. The teeth have a central cusp, rather hooked, and two secondary cusps on either side; the enamel is strongly plicated; the teeth only recently brought into use have the plicæ extending to the apex. The bases are wide, and have the rugose character so generally found in this genus. The lateral teeth present the same characters as the more central ones, but are rather smaller near the angle of the jaw. 
The central teeth, also, are rather smaller than those immediately flanking them. The teeth of the upper jaw are precisely similar to those in the lower. In neither do we find any material increase of obliquity in the cusps as they recede from the centre. The cartilaginous alæ of the mouth are distinctly traceable; they increase in width rapidly from the symphysis of the lower jaw, and attain their maximum expanse at the angle of the mouth. Behind these are some traces of the hyoidal arch. It is probable from the appearance of the matrix which envelopes it, that with a little careful cleaning a considerable portion of the head might be disclosed. In its present condition, the only part of the cranial cartilages to be distinguished is a section of the prosencephalic cavity.

The geological inferences afforded by this specimen are briefly told. 'The species is new. The genus is undoubtedly Hybodus. This genus attains its maximum expansion in the Oolitic series, but it ranges from the Muschelkalk to the Chalk inclusive. The only evidence of its occurrence in the latter formation is a fragment of an Ichthyodorulite in the Mantell collection. The teeth have not yet been found in any strata more recent than the Wealden. As far therefore as the evidence goes, it leads to the supposition that a bed containing teeth of the genus Hybodus is most likely to be of an age anterior to the cretaceous system. In a zoological point of view, this specimen is of more importance, inasmuch as it fully corroborates the views advanced by Agassiz, "that most probably the Hybodonts differed little from the recent sharks in general aspect." It also authenticates the numerous species established by that distinguished naturalist from the characters of isolafed teeth. We find in many of the recent sharks, in Carcharias for example, the discrepancy between the teeth of the upper and lower jaw so great, that it would be considered quite warrantable to describe them, if found detached, as different species. It was from a just appreciation of these difficulties that Agassiz has always professed his names and characters of the placoid teeth to be descriptive of specimens, and to be considered provisional as regards specific arrangement, until evidence should be found authorising or annulling the continuance of the titles as applicable to species. Mr. Ibbetson's specimen shows that in the genus Hybodus there was no difference between the teeth of the upper and lower jaw, and less variation, according to position, than in the recent sharks; consequently the descriptive characters given in the Poissons Fossiles will hold good as specific distinctions. The Hybodonts, then, of the secondary strata differed only from the sharks of the recent period in those modifications which adapted them to the circumstances under which they existed. The form of the mouth was nearly similar; from this we may argue a similarity of shape and an analogous arrangement of the fins to enable them to seize their prey. If they subsisted upon fish, which is most probable from the form of the teeth, we find in the denser structure and hard enamel coating of these organs, provisions to enable them to grapple with the Ganoid fishes of that period; while in the powerful fin bones with which they were armed, we 


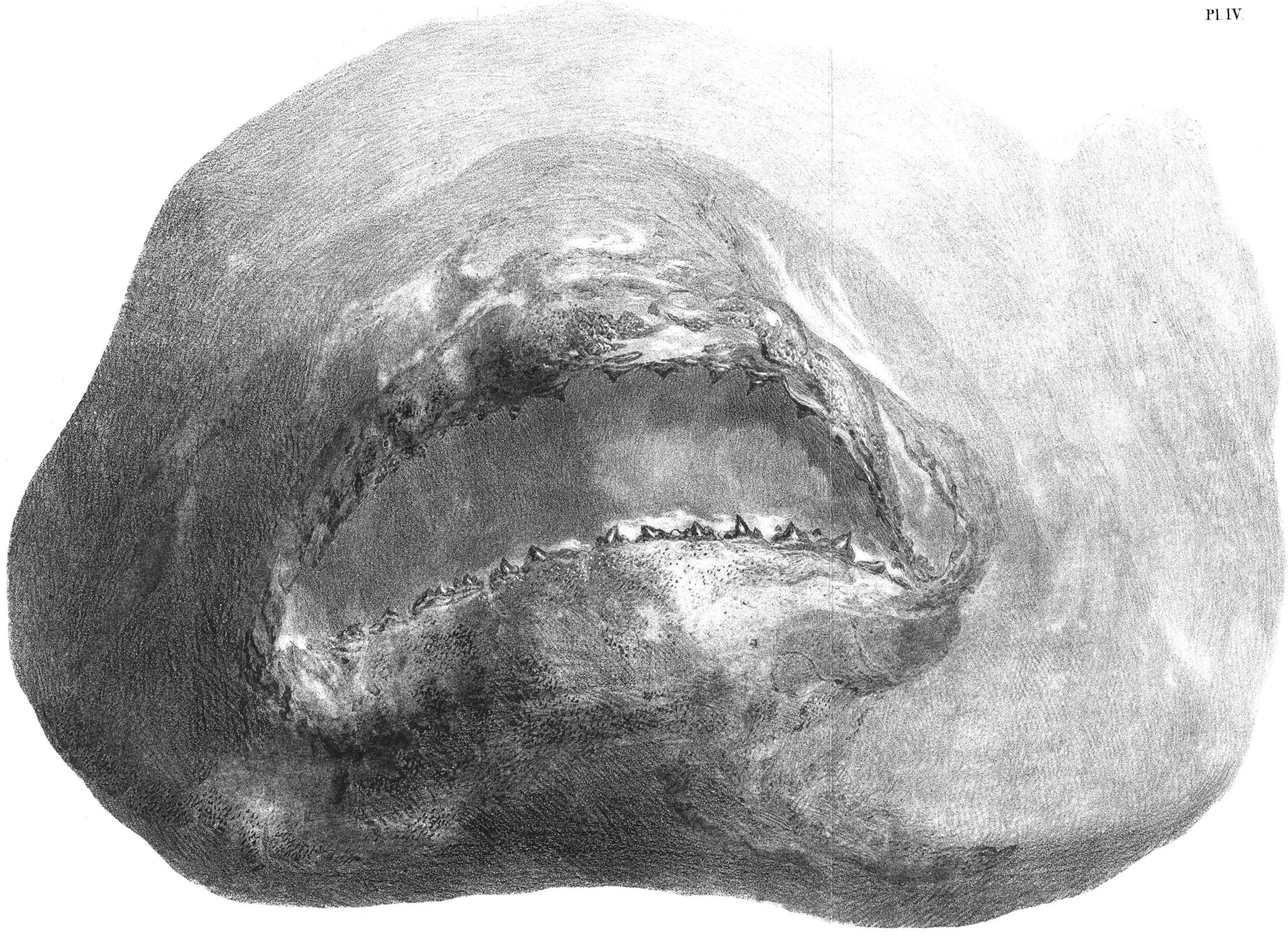


LYELL ON MASSACHUSSETTS ANTHRACITE.

see weapons of defence against the aggressions of the Piscivorous Saurians with which they were destined to coexist. I propose to name this species Hybodus basanus.*

6. Extracts were read from letters of M. Dubois de Montpereux to Mr. L. L. Boscawen Ibbetson, on the comparison of the Neocomian beds of the Caucasus and the Crimea with those of Neufchâtel, and from Professor Agassiz to Mr. Ibbetson, on the age of the Neocomian beds of Neufchâtel.

MAY 15th, 1844.

W. J. Blake, Esq., of Danesbury, was elected a Fellow of this Society.

The following communications were made :-

1. On some Crustaceous Remains in Carboniferous Rocks. By W. Ick, Esq., F.G.S.

THIs communication accompanied two electrotype casts of the specimens alluded to. The one was found in the white ironstone measures at Ridgeacre Colliery, and the author states, - "I at first thought it might be the head and carapace of a new species of Eryon except that the known species from the Solenhofen slate are much more deeply notched on the edges of the carapace, and the apparently spinous prolongation of the head and some other details do not agree. The white ironstone in which it was found is a bed in the lower part of the field below what is called the New Mine coal. It is the bed in which the finest remains of Megalichthys have been found."

"The other fossil is in an ironstone nodule. The form is not so well defined as in the first, and I dare not venture to guess to what it may be referred."

\section{On the probable Age and Origin of a Bed of Plumbago} and ANTHRACITE occurring in mica-schist near Worcester, Massachussetts. By C. Lyeli, Esq., M.A., F.R.S., F.G.S., \&c.

A BED of plumbago and impure anthracite described by Professor Hitchcock in his "Geology of Massachussetts" is found interstratified with mica-schist near Worcester, forty-five miles due west of Boston. It is about two feet in thickness, and has been made use of both as fuel and in the manufacture of lead-pencils. It is much mixed up with the associated rock, has the touch and somewhat of the lustre of plumbago, and gives a streak on paper. It is occasionally iridescent like coal, contains pyrites, which is also found in the associated clay slate and garnetiferous mica-schist,

* The accompanying plate exhibits the appcarance of the fossil embedded in the rock, and partially cleared. 